\title{
RHODOTORULA GLUTINIS Y R. RUBRA: AGENTES DE MICOSIS OPORTUNISTAS EN EL HOMBRE
}

\author{
Julio Silva, Rosa Runco de Laborda, \\ Gladys Almendro y Raquel Salim \\ Cátedra de Micología. \\ Instituto de Microbiologia "Dr. Luis C. Verna" \\ Facultad de Bioquímica, Química y Farmacia. \\ Universidad Nacional de Tucumán. \\ Ayacucho 491 (4000) San Miguel de Tucumán. Argentina
}

Palabras clave: Rhodotorula glutinis, R. rubra, micosis oportunistas

Key words: Rhodotorula glutinis, $\mathbf{R}$. rubra, opportunistic mycoses.

RESUMEN

Las levaduras del género Rhodotorula son patogenas potenciales para el hombre cuando este presenta las condiciones de terreno propicias para las micosis oportunistas. El presente trabajo tiene la finalidad de informar el aislamiento en cultivos puros y reiterados de estas levaduras en materiales clínicos de pacientes inmunocomprometidos.

De 280 muestras clínicas diversas se aislanon 4 cepas correspondientes a Rhodotorula rubra y 1 a R. glutinis.

Es posible relacionar la presencia de Rhodotorula con acción patógena en los materiales clínicos estudiados en pacientes con severo compromiso renal.

\section{INTRODUCCION}

Las micosis oportunistas producidas por algunas especies de Rhodotorula, preferentemente Rhodotorula rubra, en enfermos graves a los que se administra por cateteres, soluciones fisiológicas susceptibles de ser contaminadas u otras terapias. En estos casos la invasión generalizada puede producir lesiones en pulmón, riñones y sistema nervioso central de evolución mortal (1)(5)(7).

Se han descrito casos esporádicos de esta micosis en hospitales, bancos de sangre y como

\section{SUMMARY}

[Rhodotorula glutinis and $\mathbf{R}$, rubra: Agents of opportunistic mycoses in man.]

The members of the genus Rhodotorula are potentially pathogenic for man when the host conditions are appropriate for an opportunistic mycoses.

The present paper reports the isolation in pure cultures of this yeast in clinical samples from immunocompromised patients.

Five strains were isolated out of 280 specimens 4 of which were identified as Rhodotorula rubra and $I$ as $\mathbf{R}$. glutinis.

It is possible to correlate the presence of pathogenic Rhodotorula in the clinical samples, in patients with acute renal failure.

complicación de diálisis renal e implantaciones de válvulas cardíacas (3)(4)(6).

Las levaduras del género Rhodotorula son saprófitas y forman parte de la microbiota normal de la piel y mucosas del hombre y los animales. Están ampliamente difundidas en el ambiente y en el suelo siendo habituales contaminantes de los medios de cultivo (2).

En la literatura médica a nuestro alcance son pocos los casos informados y en general fueron diagnosticados por autopsia. Los cuadros clínicos observados en su mayoría corresponden a pacientes con compromiso renal y que sobrellevan diálisis. 
El objetivo del presente trabajo es informar el hallazgo de cultivos puros y reiterados de especies de Rhodotorula como agentes de micosis oportunistas en pacientes inmunocomprometidos

\section{MATERIALES Y METODOS}

\section{Muestras Clínicas}

De 109 pacientes internados en salas de urología, oncología, neumonología y cirugía se procesó un total de 280 muestras clínicas comprendiendo: sangre (35), orina (103), esputo (84), biopsias (16), lavado bronquial (25) y secreción de heridas (17).

\section{Aislamiento}

Fueron consideradas positivas las muestras que al examen directo presentaron abundantes levaduras brotantes, cultivos repetidos del mismo hongo en muestras clínicas seriadas o aislamiento por cultivo de biopsias. Todos los especímenes fueron sembrados en Sabouraud-glucosa-agar (SGA) con y sin el agregado de $200 \mathrm{U} / \mathrm{ml}$ de penicilina y 0,1 $\mathrm{mg} / \mathrm{ml}$ de estreptomicina. Los cultivos fueron incubados a $37^{\circ} \mathrm{C}$ y examinados después de 48 horas y hasta los 10 días de incubación.

\section{Inóculos}

Las cepas en cultivo puro fueron transplantadas nuevamente a SGA e incubadas a $37^{\circ} \mathrm{C}$ durante 16-18 horas. Las levaduras fueron cosechadas y lavadas tres veces con agua destilada estéril y centrifugadas. El pellet fue diluído con agua destilada estéril hasta una turbidez equivalente a la del tubo número 5 de la escala de McFarland. $0,2 \mathrm{ml}$ de esta suspensión celular fue inoculada al realizar las pruebas de fermentación y asimilación.

\section{Identificación}

Los cultivos fueron identificados por las siguientes características (Kreger van Rij, 1984) (2):

- caracteres macromorfológicos en SGA: colonias con pigmento carotenoide, lisas y húmedas que con los días se hacen rugosas y de aspecto más seco y mate.

- micromorfología: células levaduriformes ovoides o alargadas de $2 \times 6$ um aproximadamente.
- fermentación de carbohidratos: incapaces de fermentar azúcares. se utilizó el medio basal de solución peptonada al $1 \%$ conteniendo púrpura de bromo-cresol al 1,6\% como indicador de $\mathrm{pH}$. - asimilación de compuestos carbonados en medio basal de Lodder-agar libre de fuente carbonada. Los compuestos probados fueron: inositol, eritritol, rafinosa, maltosa, melizitosa y melibiosa.

asimilación de $\mathrm{KNO}_{3}$ al $10 \%$ en medio basal de Lodder-agar libre de fuente nitrogenada.

test de ureasa en Christensen agar: ureasa + R. rubra asimila: rafinosa y puede asimilar maltosa y melizitosa.

R. glutinis asimila: $\mathrm{KNO}_{3}$, rafinosa, maltosa $\mathrm{y}$ melizitosa.

Ambas cepas son inositol (-).

\section{RESULTADOS}

En un período de aproximadamente dos años fue posible aislar repetidamente cultivos puros de Rhodotorula rubra en 4 pacientes y Rhodotorula glutinis en uno.

Los datos que resumen las características clínicas, régimen terapéutico y aislamientos fúngicos se muestran en la Tabla 1.

Los cinco casos se presentaron en adultos entre los 16 a 60 años de edad, tres de sexo femenino y dos masculinos. Cuatro pacientes presentaron compromiso renal y el restante padecía de tuberculosis recidivante y cirugía abdominal.

Estos pacientes padecieron fiebre intermitente que no cedía con la antibioticoterapia y en ningún caso fue posible predecir clínicamente la asociación de un hongo oportunista al cuadro clínico del paciente.

\section{CONCLUSIONES}

- Es posible relacionar la presencia de Rhodotorula con acción patógena en los materiales clínicos estudiados. Coincidentemente con los informe de otros autores (6), se aísla Rhodotorula en pacientes con severo compromiso renal siendo R. rubra la especie más frecuente.

- La potencialidad de esta levadura para actuar como un patógeno oportunista deberá tenerse en cuenta en el laboratorio por lo que los cultivos positivos de Rhodotorula no serán rotulados como "solamente contaminantes" cuando sean recuperados en número importante, de manera constante y repetida. 


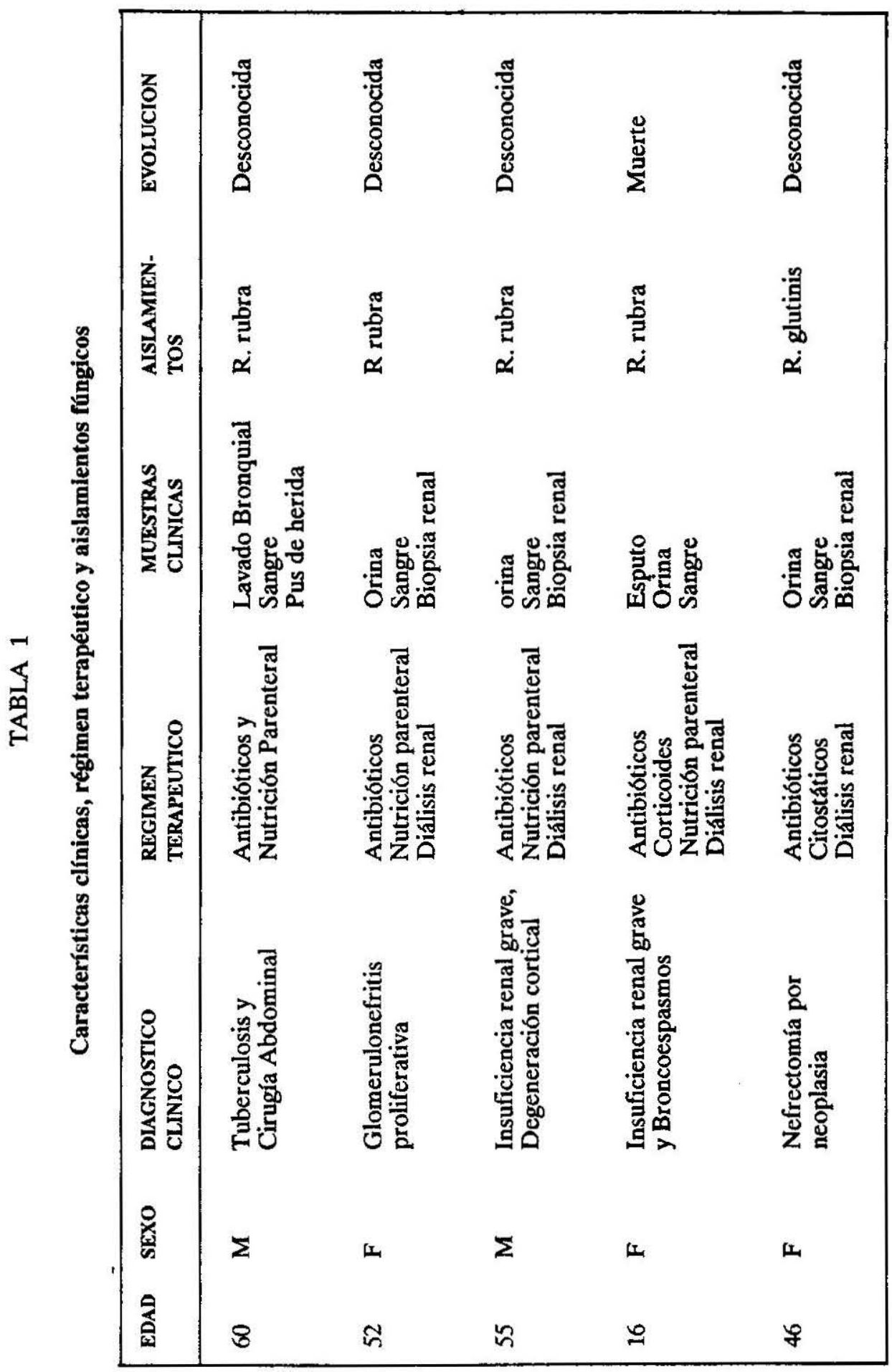




\section{REFERENCIAS}

1. EISENBERG, E., SOEIRO, R. (1986). Fungal peritonitis in patients receiving peritoneal dialysis; experiencie with 11 patients and review of the literature. Rev. Infect. Dis. 8:308-321.

2. FELL, J. STATZELL, A. \& AHEARN, D. (1984). The Yeast, a taxonomic study. Kreger-van Rij, N. J. Elsevier Science Publ. Co. Inc. New York. 3rd Ed.

3. MITTMAN, R. SOEIRO, R. \& EISENBER, E. (1983). Rhodotorula rubra peritonitis in patients undergoing continuous ambulatory peritoneal dialysis. Am. J. Med. 75: 349-352.
4. OH, S., CONLEY, S. (1985). Fungal peritonitis in children undergoing peritoneal dialysis. Pediatr. Infec. Dis. 4: 62-66.

5. PIEN, F. \& ROBERS, G. D. (1980) Two cases of Rhodotorula septicemia and a review of the literature. Mayo Clin. Proc. 55: 258-260.

6. PRICE, C. G. \& KEANE, W. F. (1981). Newer modifications of peritoneal dialysis: opportunistic mycosis in the patients with renal failure. Am. J. Nephrol. 1: 97-104.

7. RUSTHOWEN, J., FELL, R. \& TUFFNELL, P. (1984). Systemic infections by Rhodotorula spp. in the immunocompromised host. J. Infect. 8: 241-246. 